\title{
Hyperbranched poly(ether ether ketone)s: preparation and comparison of properties with the corresponding dendrimers
}

\author{
Atsushi Morikawa and Minoru Akagi \\ Hyperbranched poly(ether ether ketone)s with hydroxyl terminal groups are prepared by a one-step polycondensation of \\ 3,5-dihydroxy-4'-(4-fluorobenzoyl)diphenylether ( $A_{2}{ }_{2}$-type monomer) through an aromatic nucleophilic substitution reaction. \\ With the help of model compounds, ${ }^{1} \mathrm{H}$-NMR studies reveal that the degree of branching of the poly(ether ether ketone)s is \\ about $52 \%$. The possibility of entanglement among the hyperbranched polymer molecules is suggested from comparison of their \\ glass transition temperatures with the corresponding dendrimers and the optimized structure of the hyperbranched polymers. \\ The terminal hydroxyl groups were readily functionalized, yielding hyperbranched polymers with a variety of different functional \\ chain ends. The nature of the chain end is shown to dramatically affect the properties of the hyperbranched polymers. \\ Polymer Journal (2013) 45, 614-621; doi:10.1038/pj.2012.188; published online 14 November 2012
}

Keywords: dendrimers; entanglement; hyperbranched poly(ether ether ketone)s; optimized structure; 3, 5-dihydroxy-4'-(4fluorobenzoyl)diphenylether

\section{INTRODUCTION}

Compared with linear polymers, dendritic macromolecules are more amorphous, and are usually soluble in organic solvents because of their branched structures. Dendritic macromolecules can be classified as dendrimers or hyperbranched polymers. Dendrimers are welldefined macromolecules exhibiting precise tree-like structures, and consist of dendritic units and terminal units, whereas hyperbranched polymers consist of dendritic units, linear units and terminal units. Hyperbranched polymers possess numerous branching points and end groups, and their properties, such as high solubility, low solution viscosity and absence of entanglement, are similar to those of dendrimers. Thus, hyperbranched polymers have received considerable attention due to the expectation that their unique highly branched structures will impart unusual properties. Although dendrimers are constructed via step-by-step sequences, requiring isolation and purification after each step, hyperbranched polymers can be prepared by one-step polymerization of ABx-type monomers. As hyperbranched polymers are thought to possess similar properties to those of dendrimers and are easily prepared, many varieties of hyperbranched polymers, such as polyesters, ${ }^{1-4}$ polyamides, ${ }^{5-7}$ poly(ether ketone)s, ${ }^{8-11}$ polyphenylene, ${ }^{12}$ polyurethanes, ${ }^{13}$ polyimides, ${ }^{14-16}$ polycarbonates, ${ }^{17}$ polysiloxanes, ${ }^{18,19}$ poly(benzoxazole)s, ${ }^{20,21}$ poly(triphenylamine) $s^{22}$ and poly(ether sulfone) $\mathrm{s}^{23}$ have been prepared from ABx-type monomers and their properties have been investigated. Moreover, hyperbranched polymers were prepared from $\mathrm{A}_{2}$-type and $\mathrm{B}_{3-\text { type }}$ monomers, ${ }^{24,25}$ and hyperbranched polymers with controlled degrees of branching were also prepared.26,27 Hyperbranched polymers and dendrimers have been modified by introduction of functional groups to the chain end or chain backbone, and a variety of applications, such as encapsulators, ${ }^{11-19,28}$ composite materials, ${ }^{29-31}$ ion-exchange membranes, ${ }^{32}$ photoresistors, ${ }^{33}$ nonlinear optical devices, ${ }^{34}$ diodes $^{35}$ and cross-linkers, ${ }^{36,37}$ have been investigated. Therefore, it is thought to be important to compare the properties of hyperbranched polymers with those of the corresponding dendrimers.

In our previous paper, we synthesized poly(ether ether ketone) dendrimers by the divergent approach through an aromatic nucleophilic substitution reaction using 3,5-dimethoxy-4'-(4-fluorobenzoyl) diphenyl ether and 1,3,5-tris(p-(3,5-dihydroxyphenoxy)phenyl) benzene as a building block and a starting core, respectively. ${ }^{38}$ Den G3-OMe and Den G3-OH possessing 48 methoxy groups and hydroxyl groups on the periphery were obtained, and the periphery groups had great influence on the properties of the resulting dendrimers.

In this study, hyperbranched poly(ether ether ketone)s with hydroxyl terminal groups were prepared by a one-step polycondensation of 3,5-dihydroxy-4'-(4-fluorobenzoyl)diphenylether through an aromatic nucleophilic substitution reaction, and the properties were compared with those of the dendrimers. The hydroxyl groups at the chain end were converted to various functional groups, and the properties of the hyperbranched polymers were found to be dependent on the functional groups. 


\section{EXPERIMENTAL PROCEDURE}

${ }^{1} \mathrm{H}$ - and ${ }^{13} \mathrm{C}$ - NMR spectra were recorded on a JNM-GSX400 FT-NMR spectrometer (JEOL, Tokyo, Japan) and IR spectra were recorded on a Shimadzu spectrophotometer IR 435 (Shimadzu Corporation, Kyoto, Japan). Gel permeation chromatography was carried out on a Polymer Laboratories analytical column, PL gel $5 \mu$ MIXED-C (Polymer Laboratories LTD, Tokyo, Japan), with tetrahydrofuran as the eluent. Reduced viscosity was measured at various concentrations using an Ubbelohde-type capillary viscometer (Shibata Corporation, Sohka, Japan) in tetrahydrofuran at $30^{\circ} \mathrm{C}$. Differential scanning calorimetry was performed with a Shimadzu DSC-60 instruct (Shimadzu Corporation) and measurements were made at a heating rate of $10^{\circ} \mathrm{C} \mathrm{min}^{-1}$ in air or nitrogen from room temperature to $280^{\circ} \mathrm{C}$. Thermogravimetry (TG) was performed with a Rigaku thermal analysis station TG8110 (Rigaku Corporation, Tokyo, Japan), and measurements were made at a heating rate of $10^{\circ} \mathrm{C} \mathrm{min}^{-1}$ in air from room temperature to $800^{\circ} \mathrm{C}$.

Preparation of 3,5-dihydroxy-4'-(4-fluorobenzoyl)diphenylether 1 A mixture of 4,4'-difluorobenzophenone $(10.91 \mathrm{~g}, 0.05 \mathrm{~mol}), 3,5$-dimethoxyphenol $(7.71 \mathrm{~g}, 0.05 \mathrm{~mol})$, potassium carbonate $(6.91 \mathrm{~g}, 0.05 \mathrm{~mol})$, toluene $(25 \mathrm{ml})$ and $N, N$-dimethylacetamide (DMAc) $(45 \mathrm{ml})$ was stirred at $130{ }^{\circ} \mathrm{C}$ for $1 \mathrm{~h} .{ }^{38,39}$ The temperature was raised to $160^{\circ} \mathrm{C}$ and water formed during the reaction was removed as an azeotrope with toluene. The reaction mixture was stirred at this temperature for $1.5 \mathrm{~h}$. After the reaction was complete, the mixture was cooled to about $80^{\circ} \mathrm{C}$ and the solvent was evaporated under reduced pressure of 15-20 torr. The residue was washed with $300 \mathrm{ml}$ of water and extracted twice with $100 \mathrm{ml}$ of dichloromethane. After the combined extract was dried over anhydrous magnesium sulfate, the solvent was evaporated. The residue was distilled three times under reduced pressure (Glass tube oven) by fractional distilation to pure 3,5-dimethoxy-4'-(4-fluorobenzoyl) diphenylether. ${ }^{38}$ Yield: $8.82 \mathrm{~g}$ (50\%). Mp: $53-54^{\circ} \mathrm{C}$. Bp: $260^{\circ} \mathrm{C}$ (1 torr).

3,5-dimethoxy-4'-(4-fluorobenzoyl)diphenylether $\quad(5.29 \mathrm{~g}, 15 \mathrm{mmol})$ was heated together with pyridine hydrochloride $(30 \mathrm{~g})$ at reflux temperature $\left(240^{\circ} \mathrm{C}\right)$ for about $30 \mathrm{~min}$. After the reaction mixture was homogeneous, it was poured into water $(500 \mathrm{ml})$, and extracted twice with $100 \mathrm{ml}$ of ethyl acetate. The combined extract was dried over anhydrous magnesium sulfate. After the solvent was evaporated, pure 1 was obtained by silica gel column eluted by dichloromethane and ethyl acetate (2: 1). ${ }^{39}$ Yield: $4.23 \mathrm{~g}(87 \%)$. Mp: $137-138{ }^{\circ} \mathrm{C}$.

The IR spectrum exhibited absorption bands at $3400-3000 \mathrm{~cm}^{-1}(\mathrm{OH})$, $1640 \mathrm{~cm}^{-1}(\mathrm{C}=\mathrm{O})$, and $1240 \mathrm{~cm}^{-1}$ (Ar-O-Ar).

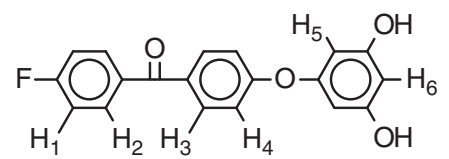

The ${ }^{1} \mathrm{H}$ NMR spectrum $\left(\delta\right.$ in $\left.\mathrm{CDCl}_{3}\right)$ showed signals at $5.40(\mathrm{~s}, 2 \mathrm{H}, \mathrm{OH})$, 6.15 (d, $2 \mathrm{H}, J=2.2 \mathrm{~Hz}, \mathrm{H} 5), 6.19$ (t, $1 \mathrm{H}, J=2.2 \mathrm{~Hz}, \mathrm{H} 6), 7.06$ (d, $2 \mathrm{H}, J=8.8$ $\mathrm{Hz}, \mathrm{H} 4), 7.16(\mathrm{~m}, 2 \mathrm{H}, \mathrm{H} 1), 7.77(\mathrm{~d}, 2 \mathrm{H}, J=8.8 \mathrm{~Hz}, \mathrm{H} 3)$ and $7.81(\mathrm{~m}, 2 \mathrm{H}, \mathrm{H} 2)$. The ${ }^{13} \mathrm{C}$ NMR spectrum ( $\delta$ in in $\mathrm{CDCl}_{3}$ ) showed signals at 99.28, $99.88,115.53(\mathrm{~d}, J=22.3 \mathrm{~Hz}), 117.92,132.09,132.31,132.55(\mathrm{~d}, J=9.5 \mathrm{~Hz})$, $133.89(\mathrm{~d}, J=3.2 \mathrm{~Hz}), \quad 157.66, \quad 157.88, \quad 160.99,165.37(\mathrm{~d}, J=234.3 \mathrm{~Hz})$ and 194.61 .

Anal. Calcd for $\mathrm{C}_{19} \mathrm{H}_{13} \mathrm{FO}_{4}$ : C, 70.37\%; H, 4.04\%. Found: C, 70.48\%; H, $4.15 \%$.

\section{Preparation of hyperbranched poly(ether ether ketone) P1}

A mixture of 1 ( $1.62 \mathrm{~g}, 5 \mathrm{mmol})$, potassium carbonate $(0.373 \mathrm{~g}, 2.7 \mathrm{mmol})$, toluene $(10 \mathrm{ml})$ and DMAc $(20 \mathrm{ml})$ was stirred in a flask at $120^{\circ} \mathrm{C}$. The temperature was then raised from $120^{\circ} \mathrm{C}$ to $165^{\circ} \mathrm{C}$, to remove water formed during the reaction as an azeotrope with toluene. The reaction mixture was stirred at this temperature for $6 \mathrm{~h}$. The polymerization proceeded homogeneously. After the reaction was completed, the mixture was cooled to room temperature and poured into $300 \mathrm{ml}$ of methanol. The precipitated polymer was collected by filtration, washed thoroughly with water and methanol, and dried under vacuum. Yield: $1.34 \mathrm{~g}(88 \%)$.
The IR spectrum exhibited absorption bands at $3400-3000 \mathrm{~cm}^{-1}(\mathrm{OH})$, $1650 \mathrm{~cm}^{-1}(\mathrm{C}=\mathrm{O})$ and $1240 \mathrm{~cm}^{-1}(\mathrm{Ar}-\mathrm{O}-\mathrm{Ar})$.

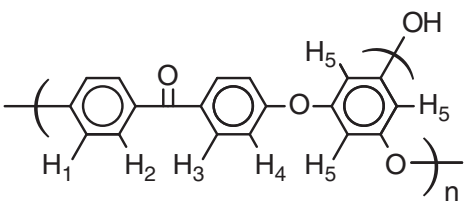

The ${ }^{1} \mathrm{H}$ NMR spectrum $\left[\delta\right.$ in DMSO- $d_{6}$ ] showed signals at $5.90-5.96(0.64 \mathrm{H}$, H5 terminal unit), 6.04-6.08 (0.32H, H5 terminal unit), 6.24-6.31 $(0.51 \mathrm{H}, \mathrm{H} 5$ linear unit), 6.31-6.36 (1.03H, H5 linear unit), 6.64-6.72 (0.51H, H5 dendritic unit), 7.00-7.30 (4H,H1 and $\mathrm{H} 4)$, and 7.58-7.86 (4H, $\mathrm{H} 2$ and $\mathrm{H} 3)$ p.p.m.

Anal. Calcd for $\mathrm{C}_{19} \mathrm{H}_{12} \mathrm{O}_{4}$ : C, 74.99\%; H, 3.97\%. Found: C, 74.52\%; $\mathrm{H}, 3.64 \%$

\section{Preparation of the model compound}

4-benzoyl-3, 5-dimethoxy-diphenylether 2. A mixture of 4-fluorobenzophenone $(5.00 \mathrm{~g}, 25 \mathrm{mmol}), 3,5$-dimethoxyphenol $(3.85 \mathrm{~g}, 25 \mathrm{mmol})$, potassium carbonate $(1.93 \mathrm{~g}, 14 \mathrm{mmol})$, toluene $(30 \mathrm{ml})$ and DMAc $(60 \mathrm{ml})$ was stirred in a flask at $120^{\circ} \mathrm{C}$. The temperature was then raised from 120 to $165^{\circ} \mathrm{C}$ to remove water formed during the reaction as an azeotrope with toluene. The reaction mixture was stirred at this temperature for $6 \mathrm{~h}$, and cooled to $80^{\circ} \mathrm{C}$, and the solvent was evaporated under reduced pressure of 15-20 torr. The residue was washed with $300 \mathrm{ml}$ of water and extracted twice with $100 \mathrm{ml}$ of dichloromethane. The combined organic layer was dried over anhydrous magnesium sulfate. After evaporation of the solvent, the residue was distilled under reduced (ceramic heater) pressure to give pure 2. Yield: $6.02 \mathrm{~g}(72 \%)$. Bp. $240{ }^{\circ} \mathrm{C}$ ( 1 torr). Mp. $62-64^{\circ} \mathrm{C}$.

The IR spectrum exhibited absorption bands at $2940 \mathrm{~cm}^{-1}\left(\mathrm{CH}_{3}\right)$, $1650 \mathrm{~cm}^{-1}(\mathrm{C}=\mathrm{O})$ and $1240 \mathrm{~cm}^{-1}$ (Ar-O-Ar).<smiles>[2H]c1cccc(C(=O)c2ccc(Oc3cc(OC)cc(OC)c3C)c(C)c2C)c1C</smiles>

The ${ }^{1} \mathrm{H}$ NMR spectrum ( $\delta$ in DMSO- $d_{6}$ ) showed signals at $3.77(\mathrm{~s}, 6 \mathrm{H}$, $\left.-\mathrm{CH}_{3}\right), 5.94(\mathrm{~d}, 2 \mathrm{H}, J=2.2 \mathrm{~Hz}, \mathrm{H} 6), 6.09(\mathrm{t}, 1 \mathrm{H}, J=2.2 \mathrm{~Hz}, \mathrm{H} 7), 7.10(\mathrm{~d}, 2 \mathrm{H}$, $J=8.8 \mathrm{~Hz}, \mathrm{H} 5), 7.52-7.58(\mathrm{~m}, 2 \mathrm{H}, \mathrm{H} 2), 7.64-7.69(\mathrm{~m}, 1 \mathrm{H}, \mathrm{H} 1), 7.72-7.73$ $(\mathrm{m}, 2 \mathrm{H}, \mathrm{H} 3)$ and $7.79(\mathrm{~d}, 2 \mathrm{H}, J=8.8 \mathrm{~Hz}, \mathrm{H} 4)$ p.p.m. The ${ }^{13} \mathrm{C}$ NMR spectrum $\left(\delta\right.$ in DMSO- $\left.d_{6}\right)$ showed signals at $55.6,97.8,98.8,117.4,128.1,128.8,131.5$, $131.7,131.9,137.2,156.9,159.5,160.7$ and 194.3.

Anal. Calcd for $\mathrm{C}_{21} \mathrm{H}_{18} \mathrm{O}_{2}$ : C, 75.43\%; H, 5.43\%. Found: C, 75.23\%; H, 5.24\%.

3(4-benzoylphenoxy) resorcinol 3. $2(6.02 \mathrm{~g}, 18 \mathrm{mmol})$ was heated together with pyridine hydrochroride $(40 \mathrm{~g})$ at reflux temperature $\left(240{ }^{\circ} \mathrm{C}\right)$ for about $30 \mathrm{~min}$. After the reaction mixture was homogeneous, it was poured into water $(400 \mathrm{ml})$ and extracted twice with $100 \mathrm{ml}$ of ethyl acetate. The combined organic layer was dried over anhydrous magnesium sulfate, and the solvent was evaporated. Pure 3 was obtained by silica gel column chromatography with dichloromethane and ethyl acetate (10:1). Yield: $4.68 \mathrm{~g}(85 \%)$. Mp. $52-53^{\circ} \mathrm{C}$.

The IR spectrum exhibited absorption bands at $3400-3000 \mathrm{~cm}^{-1}(\mathrm{OH})$, $1650 \mathrm{~cm}^{-1}(\mathrm{C}=\mathrm{O})$ and $1240 \mathrm{~cm}^{-1}$ (Ar-O-Ar).<smiles>Cc1c(O)cccc1C(=O)c1ccc(Oc2cc(O)c(O)c(C)c2C)c(C)c1C</smiles>

The ${ }^{1} \mathrm{H}$ NMR spectrum $\left(\delta\right.$ in DMSO- $\left.d_{6}\right)$ showed signals at $5.95(\mathrm{~d}, 2 \mathrm{H}$, $J=2.2 \mathrm{~Hz}, \mathrm{H} 6), 6.10(\mathrm{t}, 1 \mathrm{H}, J=2.2 \mathrm{~Hz}, \mathrm{H} 7), 7.10(\mathrm{~d}, 2 \mathrm{H}, J=8.8 \mathrm{~Hz}, \mathrm{H} 5)$, 7.53-7.58 (m, 2H, H2), 7.64-7.68 (m, 1H, H1), 7.72-7.73 (m, 2H, H3), 7.77 (d, $2 \mathrm{H}, J=8.8 \mathrm{~Hz}, \mathrm{H} 4)$ and 9.38 (s, $2 \mathrm{H} \mathrm{OH})$ p.p.m. The ${ }^{13} \mathrm{C}$ NMR spectrum $\left(\delta\right.$ in DMSO- $d_{6}$ ) showed signals at $97.5,98.8,117.2,127.9,128.8,131.3,131.5$, 131.7, 137.2, 156.6, 159.3, 160.7 and 194.1.

Anal. Calcd for $\mathrm{C}_{19} \mathrm{H}_{14} \mathrm{O}_{4}$ : C, $74.50 \% ; \mathrm{H}, 4.61 \%$. Found: C, $74.36 \%$; $\mathrm{H}, 4.43 \%$. 
3,5-bis(4-benzoylphenoxy)phenol 4 and 1,3,5-tris(benzoylphenoxy)benzene 5. A mixture of 4-fluorobenzophenone $(3.00 \mathrm{~g}, 15 \mathrm{mmol}), 3(4.59 \mathrm{~g}, 15 \mathrm{mmol})$, potassium carbonate $(1.24 \mathrm{~g}, 9 \mathrm{mmol})$, toluene $(30 \mathrm{ml})$ and DMAc $(60 \mathrm{ml})$ was stirred in a flask at $120^{\circ} \mathrm{C}$. The temperature was then raised from 120 to $165^{\circ} \mathrm{C}$, to remove water formed during the reaction as an azeotrope with toluene. The reaction mixture was stirred at this temperature for $6 \mathrm{~h}$, then cooled to $80^{\circ} \mathrm{C}$, and the solvent was evaporated under reduced pressure of $15-20$ torr. The residue was washed with $300 \mathrm{ml}$ of water and extracted twice with $100 \mathrm{ml}$ of dichloromethane. The combined organic layer was dried over anhydrous magnesium sulfate. After evaporation of the solvent, a mixture of 4 and 5 was obtained. Pure 4 and 5 were obtained by silica gel column chromatography with dichloromethane and ethylacetate (40:1).

3,5-bis(4-benzoylphenoxy)phenol (4). Yield:1.92 g. Mp. 82-84 ${ }^{\circ} \mathrm{C}$.

The IR spectrum exhibited absorption bands at $3400-3000 \mathrm{~cm}^{-1}(\mathrm{OH})$, $1650 \mathrm{~cm}^{-1}(\mathrm{C}=\mathrm{O})$ and $1240 \mathrm{~cm}^{-1}(\mathrm{Ar}-\mathrm{O}-\mathrm{Ar})$.

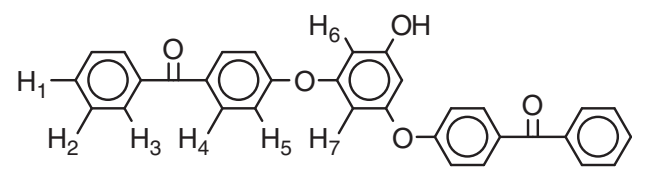

The ${ }^{1} \mathrm{H}$ NMR spectrum $\left(\delta\right.$ in DMSO- $\left.d_{6}\right)$ showed signals at $6.30(\mathrm{t}, 1 \mathrm{H}$, $J=2.2 \mathrm{~Hz}, \mathrm{H} 7), 6.37$ (d, $2 \mathrm{H}, J=2.2 \mathrm{~Hz}, \mathrm{H6}), 7.18$ (d, $2 \mathrm{H}, J=8.8 \mathrm{~Hz}, \mathrm{H} 5)$, 7.53-7.58 (m, 2H, H2), 7.66-7.69 ( $\mathrm{m}, 1 \mathrm{H}, \mathrm{H1}), 7.69-7.73$ ( $\mathrm{m}, 1 \mathrm{H}, \mathrm{H} 3), 7.81$ (d, $2 \mathrm{H}, J=8.8 \mathrm{~Hz}, \mathrm{H} 4)$ and $9.95(\mathrm{~s}, 1 \mathrm{H}, \mathrm{OH})$ p.p.m. The ${ }^{13} \mathrm{C}$ NMR spectrum $\left(\delta\right.$ in DMSO- $d_{6}$ ) showed signals at 101.2, 102.5, 116.0, 117.8, 128.0, 128.8, $131.7,131.8,132.2,137.2,157.3,160.0$ and 194.1.

Anal. Calcd for $\mathrm{C}_{32} \mathrm{H}_{22} \mathrm{O}_{5}$ : C, 79.00\%; H, 4.56\%. Found: C, 79.02\%; H, 4.54\%. 1,3,5-tris(benzoyphenoxy)benzene (5). Yield:1.92 g. Mp. $95-96^{\circ} \mathrm{C}$.

The IR spectrum exhibited absorption bands at $1650 \mathrm{~cm}^{-1}(\mathrm{C}=\mathrm{O})$ and $1240 \mathrm{~cm}^{-1}$ (Ar-O-Ar).

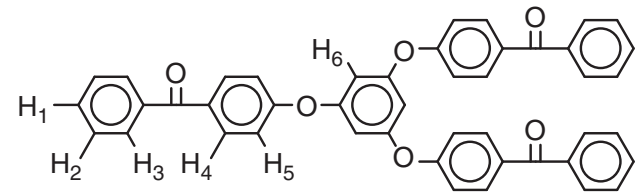

The ${ }^{1} \mathrm{H}$ NMR spectrum ( $\delta$ in DMSO- $d_{6}$ ) showed signals at 6.73 (s, 3H, H6), 7.23 (d, 6H, $J=2.2 \mathrm{~Hz}, \mathrm{H} 6), 7.49-7.54$ (m, 6H, H2), 7.63-7.66 $(\mathrm{m}, 3 \mathrm{H}, \mathrm{H1}), 7.68-7.71(\mathrm{~m}, 6 \mathrm{H}, \mathrm{H} 3)$ and $7.88(\mathrm{~d}, 2 \mathrm{H}, J=8.8 \mathrm{~Hz}, \mathrm{H} 4)$ p.p.m. The ${ }^{13} \mathrm{C}$ NMR spectrum ( $\delta$ in DMSO- $d_{6}$ ) showed signals at $106.2,117.8,128.1$, 129.0, 131.6, 132.0, 132.3, 137.0, 157.6 and 194.2.

Anal. Calcd for $\mathrm{C}_{45} \mathrm{H}_{30} \mathrm{O}_{6}$ : C, $81.70 \% ; \mathrm{H}, 4.54 \%$; N, 5.38\%. Found: $\mathrm{C}$, $81.41 \%$; H, $4.38 \%$.

\section{Preparation of hyperbranched poly(ether ether ketone) P2.}

A mixture of 1 ( $1.62 \mathrm{~g}, 5 \mathrm{mmol})$, potassium carbonate $(0.373 \mathrm{~g}, 2.7 \mathrm{mmol})$, toluene $(10 \mathrm{ml})$ and DMAc $(20 \mathrm{ml})$ was stirred in a flask at $120^{\circ} \mathrm{C}$. The temperature was then raised from 120 to $165^{\circ} \mathrm{C}$ to remove water formed during the reaction as an azeotrope with toluene, and the reaction mixture was stirred at this temperature for $6 \mathrm{~h}$. After the reaction mixture was cooled to room temperature, methyl sulfate $(0.38 \mathrm{~g}, 3 \mathrm{mmol})$ and potassium carbonate $(0.42 \mathrm{~g}, 3 \mathrm{mmol})$ were added. The mixture was stirred at $80^{\circ} \mathrm{C}$ for another $6 \mathrm{~h}$, cooled to room temperature and poured into $300 \mathrm{ml}$ of methanol. The precipitated polymer was collected by filtration, washed thoroughly with water and methanol, and dried under vacuum. Yield: $1.35 \mathrm{~g}(85 \%)$.

The IR spectrum exhibited absorption bands at $2945 \mathrm{~cm}^{-1}\left(\mathrm{CH}_{3}\right)$, $1650 \mathrm{~cm}^{-1}(\mathrm{C}=\mathrm{O})$ and $1240 \mathrm{~cm}^{-1}$ (Ar-O-Ar).

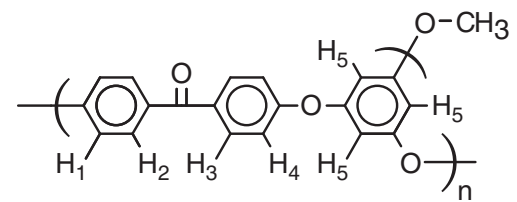

The ${ }^{1} \mathrm{H}$ NMR spectrum $\left(\delta\right.$ in DMSO- $\left.d_{6}\right)$ showed signals at $3.75-3.81(3 \mathrm{H}$, $\left.\mathrm{CH}_{3}\right), 5.93-6.00(0.65 \mathrm{H}, \mathrm{H} 5$ terminal unit), 6.07-6.011 $(0.33 \mathrm{H}, \mathrm{H} 5$ terminal unit), 6.24-6.31 (0.50H, H5 linear unit), 6.31-6.36 (1.00H, H5 linear unit), 6.64-6.72 $(0.52 \mathrm{H}, \mathrm{H} 5$ dendritic unit), $7.00-7.30(4 \mathrm{H}, \mathrm{H} 1$ and $\mathrm{H} 4)$ and 7.58-7.86 (4H, $\mathrm{H} 2$ and $\mathrm{H} 3)$ p.p.m.

Anal. Calcd for $\mathrm{C}_{20} \mathrm{H}_{14} \mathrm{O}_{4}$ : C, 75.46\%; H, 4.43\%. Found: C, $75.05 \% ; \mathrm{H}$, $4.23 \%$.

\section{Preparation of hyperbranched poly(ether ether ketone) P3}

A mixture of 1 ( $1.62 \mathrm{~g}, 5 \mathrm{mmol})$, potassium carbonate $(0.373 \mathrm{~g}, 2.7 \mathrm{mmol})$, toluene $(10 \mathrm{ml})$ and DMAc $(20 \mathrm{ml})$ was stirred in a flask at $120^{\circ} \mathrm{C}$. The temperature was then raised from 120 to $165^{\circ} \mathrm{C}$ to remove water formed during the reaction as an azeotrope with toluene, and the reaction mixture was stirred at this temperature for $6 \mathrm{~h}$. After the reaction mixture was cooled to room temperature, 1-bromohexane $(0.50 \mathrm{~g}, 3 \mathrm{mmol})$ and potassium carbonate $(0.42 \mathrm{~g}, 3 \mathrm{mmol})$ were added. The mixture was stirred at $80^{\circ} \mathrm{C}$ for another $6 \mathrm{~h}$, cooled to room temperature and poured into $300 \mathrm{ml}$ of methanol. The precipitated polymer was collected by filtration, washed thoroughly with water and methanol and dried under vacuum. Yield: $1.47 \mathrm{~g}(76 \%)$.

The IR spectrum exhibited absorption bands at $2940-2960 \mathrm{~cm}^{-1}\left(\mathrm{C}_{6} \mathrm{H}_{13}\right)$, $1650 \mathrm{~cm}^{-1}(\mathrm{C}=\mathrm{O})$ and $1240 \mathrm{~cm}^{-1}(\mathrm{Ar}-\mathrm{O}-\mathrm{Ar})$.

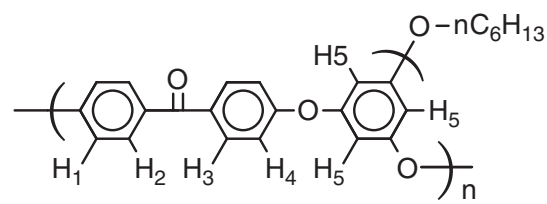

The ${ }^{1} \mathrm{H}$ NMR spectrum ( $\delta$ in DMSO- $\left.d_{6}\right)$ showed signals at $0.82-1.23(9 \mathrm{H}$, $\left.-\mathrm{CH}_{2} \mathrm{CH}_{2} \mathrm{CH}_{2} \mathrm{CH}_{2} \mathrm{CH}_{2} \mathrm{CH}_{3}\right), \quad 1.80-1.83\left(2 \mathrm{H}, \quad-\mathrm{CH}_{2} \mathrm{CH}_{2} \mathrm{CH}_{2} \mathrm{CH}_{2} \mathrm{CH}_{2} \mathrm{CH}_{3}\right)$ 3.70-3.79 (3H, $\left.-\mathrm{CH}_{2} \mathrm{CH}_{2} \mathrm{CH}_{2} \mathrm{CH}_{2} \mathrm{CH}_{2} \mathrm{CH}_{3}\right), 5.93-6.01(0.65 \mathrm{H}, \mathrm{H} 5$ terminal unit), 6.07-6.11 (0.33 H, H5 terminal unit), 6.24-6.32 (0.50H, H5 linear unit), 6.31-6.36 (1.00H, H5 linear unit), 6.64-6.72 (0.52H, H5 dendritic unit), 7.00$7.30(4 \mathrm{H}, \mathrm{H} 1$ and $\mathrm{H} 4)$ and $7.58-7.86(4 \mathrm{H}, \mathrm{H} 2$ and $\mathrm{H} 3)$ p.p.m.

Anal. Calcd for $\mathrm{C}_{25} \mathrm{H}_{24} \mathrm{O}_{4}$ : C, 77.30\%; H, 6.23\%. Found: C, 77.10\%; H, 5.98\%.

\section{Preparation of hyperbranched poly(ether ether ketone) P4}

A mixture of 1 (1.62 g, $5 \mathrm{mmol})$, potassium carbonate $(0.373 \mathrm{~g}, 2.7 \mathrm{mmol})$, toluene $(10 \mathrm{ml})$ and DMAc $(20 \mathrm{ml})$ was stirred in a flask at $120^{\circ} \mathrm{C}$. The temperature was then raised from 120 to $165^{\circ} \mathrm{C}$ to remove water formed during the reaction as an azeotrope with toluene, and the reaction mixture was stirred at this temperature for $6 \mathrm{~h}$. After the reaction mixture was cooled to room temperature, benzoyl chloride $(0.42 \mathrm{~g}, 3 \mathrm{mmol})$ and triethylamine $(0.30 \mathrm{~g}$, $3 \mathrm{mmol}$ ) were added. The mixture was stirred at room temperature for another $6 \mathrm{~h}$, cooled to room temperature, and poured into $300 \mathrm{ml}$ of methanol. The precipitated polymer was collected by filtration, washed thoroughly with water and methanol, and dried under vacuum. Yield: $1.85 \mathrm{~g}(91 \%)$.

The IR spectrum exhibited absorption bands at $1720 \mathrm{~cm}^{-1}(\mathrm{C}=\mathrm{O})$, $1650 \mathrm{~cm}^{-1}(\mathrm{C}=\mathrm{O})$ and $1240 \mathrm{~cm}^{-1}$ (Ar-O-Ar).

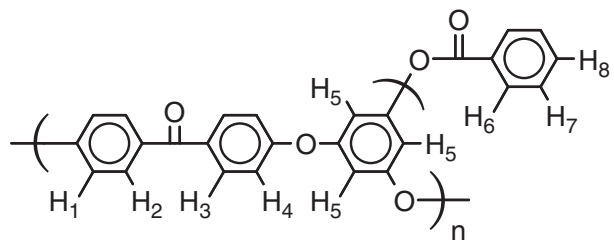

The ${ }^{1} \mathrm{H}$ NMR spectrum ( $\delta$ in DMSO- $d_{6}$ ) showed signals at $5.94-6.01$ $(0.64 \mathrm{H}, \mathrm{H} 5$ terminal unit), 6.09-6.13 $(0.32 \mathrm{H}, \mathrm{H} 5$ terminal unit), 6.23-6.33 (0.51H, H5 linear unit), 6.33-6.38 (1.03H, H5 linear unit), 6.65-6.73 $(0.51 \mathrm{H}$, H5 dendritic unit), 7.00-7.88 (9H, H1, H2, H3, H4, H6, H7 and H8) p.p.m. Anal. Calcd for $\mathrm{C}_{26} \mathrm{H}_{16} \mathrm{O}_{5}$ : C, 76.46\%; H, 3.95\%. Found: C, 76.05\%; H, 3.72\%.

\section{RESULTS AND DISCUSSION}

Polymer synthesis

The $\mathrm{AB}_{2}$-type monomer, 3,5-dihydroxy-4'-(4-fluorobenzoyl)diphenylether $\mathbf{1}$, was synthesized according to the previous method..$^{38,39}$ 
3,5-dimethoxy-4'-(4-fluorobenzoyl)diphenylether was synthesized by the reaction between 4,4'-difluorobenzophenone and 3,5dimethoxyphenol, and the 3,5-methoxy-4'-(4-fluorobenzoyl) diphenylether was treated with pyridine hydrochloride to give $\mathbf{1}$. Poly((ether)-(ether ether ketone))dendrimers were also prepared using 1 as a building block. ${ }^{39}$

Hyperbranched polymers were synthesized by the method similar to that of poly(ether ether ketone) dendrimers. ${ }^{39}$ The polymer linkages are formed by aromatic nucleophilic substitution of an activated aromatic fluoride with a phenol group in the presence of a suitable base such as potassium carbonate (Figure 1). Polymerization proceeded at $120-165^{\circ} \mathrm{C}$ using a mixture of DMAc and toluene as the solvent. The water formed during the reaction was removed as an azeotrope to promote the polymerization. The polymerization proceeded homogeneously, and the corresponding hydroxyl terminated hyperbranched poly(ether ether ketone), P1, was generated in $88 \%$ yield. Gel permeation chromatography analysis of P1 gave a $M n$ of 5200 and a $M w$ of $20300(M w / M n=3.9)$ (Figure 2). Those of the corresponding dendrimers are also shown in Figure 2 for comparison. The molecular weight of the polymer was calibrated against polystyrene. The polymerization was also carried out at $120-200^{\circ} \mathrm{C}$ using a mixture of NMP ( $\mathrm{N}$-methyl-2-pyrrolidinone) and toluene as a solvent. Mn and Mw of the obtained polymer were 4800 and 20600 , respectively, and not very dependent on the solvent or the reaction temperature.

\section{Degree of branching}

Hyperbranched polymer P1 was formed by a sequence of condensations of the $\mathrm{AB}_{2}$-type monomers resulting in an irregular dendritic structure. This structure included terminal units, $\mathbf{T}$, which have two hydroxyl groups, linear units, L, which have one hydroxyl group, and
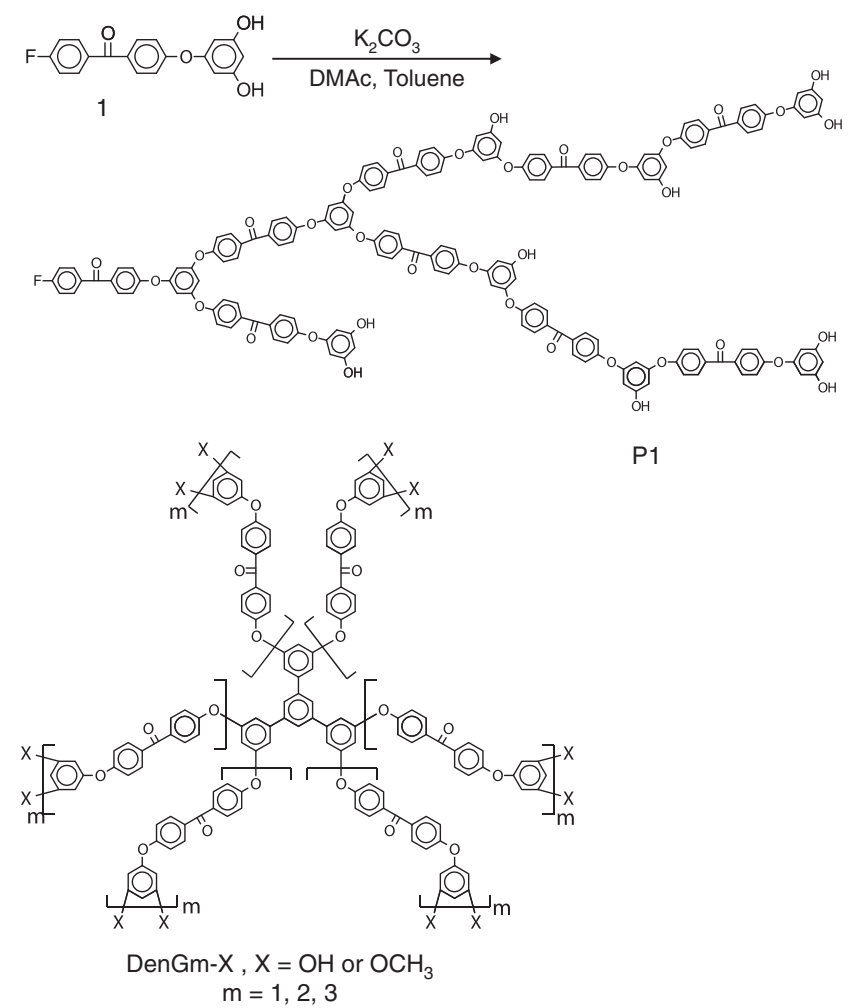

P1

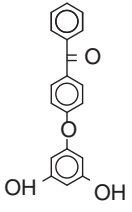

3

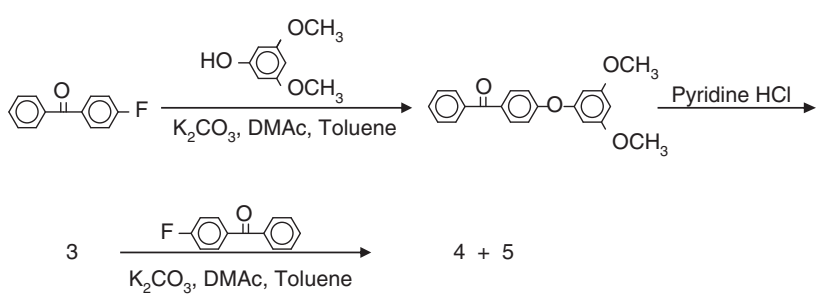

Figure 3 Model compounds 3, 4 and 5, and the synthetic procedures.

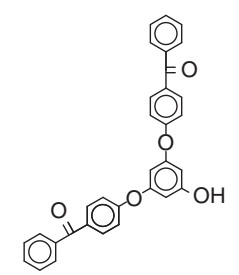

4

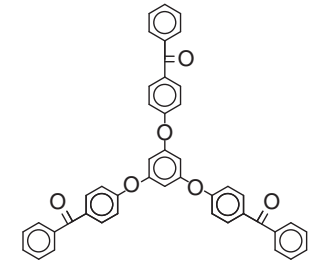

5

Polymer Journal dendritic units, D, which have no hydroxyl groups. The degree of branching $(\mathrm{DB})$ of hyperbranched polymers is given by

$\mathrm{DB}=[($ number of dendritic units $)+($ number of terminal units $)] /$ (number of total units).

As the chemical environment of the trisubstituted aromatic ring of T, $\mathbf{L}$ and $\mathbf{D}$ will be substantially different, the relative percentage of $\mathbf{T}$, $\mathbf{L}$ and $\mathbf{D}$ can be evaluated by ${ }^{1} \mathrm{H}-\mathrm{NMR}$ spectroscopy. To discriminate the three subunits of the polymer backbone, model compounds 3, 4 and 5 were synthesized (Figure 3 ). The ${ }^{1} \mathrm{H}-\mathrm{NMR}$ spectra for model compounds 3, 4, 5 and $\mathbf{P 1}$ are shown in Figure 4. That of the corresponding dendrimer DenG3-OH is also shown in Figure 4 for comparison. Distinct resonances for the terminal model compound 3 appeared at 5.95 p.p.m. (H6) and 6.10 p.p.m. (H7), whereas the corresponding resonances for the linear model compound 4 appeared at 6.37 p.p.m. (H6) and 6.30 p.p.m. (H7). H6 protons of the dendritic model compound 5 were observed at 6.73 p.p.m. In the ${ }^{1} \mathrm{H}-\mathrm{NMR}$ spectrum of DenG3-OH, the corresponding protons for the terminal units were observed at 5.93 p.p.m. and 6.08 p.p.m. and those for the dendritic units were observed at 6.55, 6.61 and 6.63 p.p.m. ${ }^{38}$ Good correlation was observed in the comparison of the ${ }^{1} \mathrm{H}-\mathrm{NMR}$ spectra of these model compounds with that of the hyperbranched polymer P1. The resonances at 5.90-5.96 p.p.m. and 6.04-6.08 p.p.m. are attributed to protons of the terminal subunit, those of

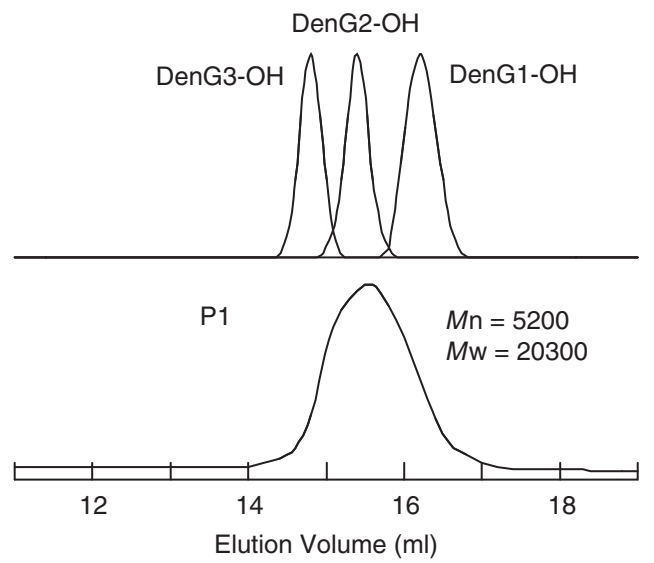

Figure 2 Gel permeation chromatography chromatograms of P1 and the corresponding dendrimers.

Figure 1 Synthesis of hyperbranched poly(ether ether ketone) and structures of the corresponding dendrimers. 

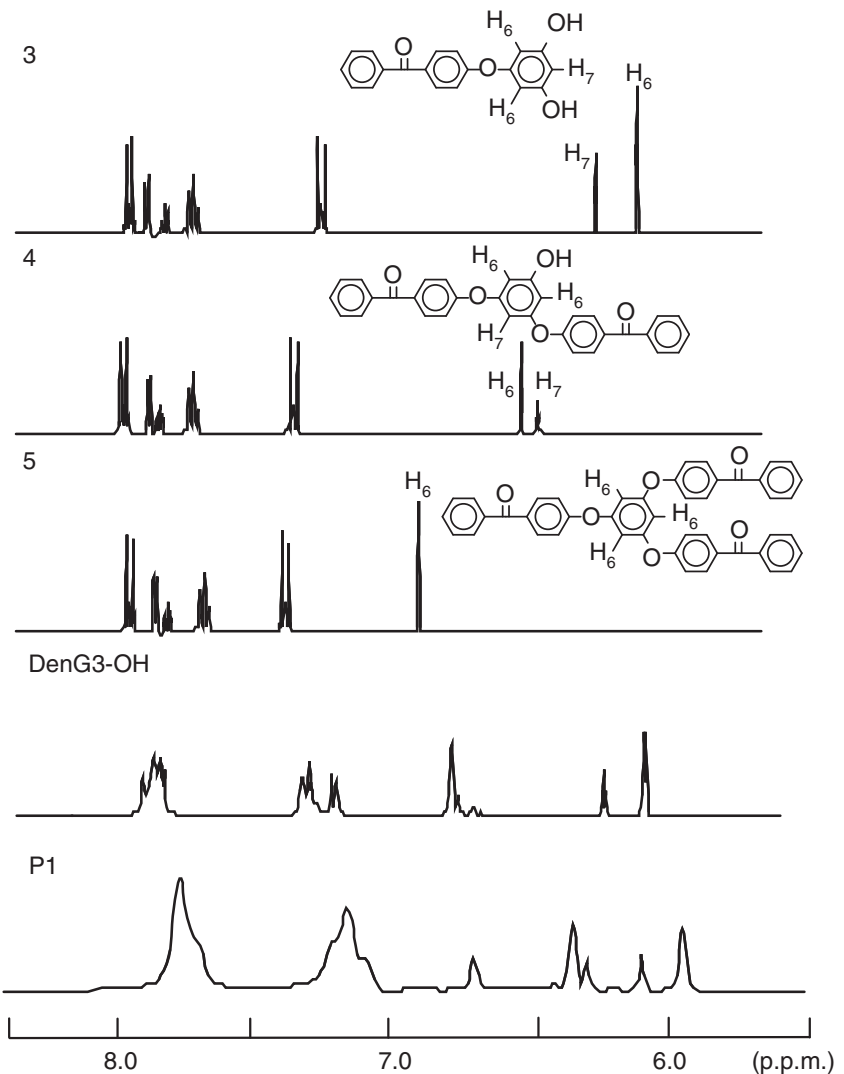

Figure 4 Comparison of ${ }^{1} \mathrm{H}$-NMR spectrum for the hyperbranched polymer P1 with those of the terminal, linear and dendritic model compounds, 3, 4 and $\mathbf{5}$, respectively.

6.24-6.31 p.p.m. and 6.31-6.36 p.p.m. are attributed to protons of the linear subunit, and that of 6.64-6.72 p.p.m. is attributed to protons of the dendritic subunit. Integration of the resonances provided the relative percentage of the three subunits in the hyperbranched polymer of $\mathbf{P 1}$, and the DB of $\mathbf{P 1}$ was evaluated to be 0.52 .

When the ${ }^{1} \mathrm{H}$-NMR spectrum for $\mathbf{P 1}$ is compared with that of DenG3-OH, the signals for the terminal units have nearly the same chemical shift, but the signals for dendritic units in P1 appear downfield from those in DenG3-OH. The environment of dendritic units in $\mathbf{P} 1$ could be evaluated by the ${ }^{1} \mathrm{H}-\mathrm{NMR}$ spectrum for dendritic units in P1 compared with those of the corresponding dendrimers DenG1-OH, DenG2-OH and DenG3-OH (Figure 5). The signals for Ha in DenG1-OH, DenG2-OH and DenG3-OH appear at 6.63 p.p.m., 6.59 p.p.m. and 6.55 p.p.m., respectively, and those for $\mathrm{Hb}$ in DenG2-OH and DenG3-OH appear at 6.66 p.p.m. and 6.61 p.p.m., respectively. The signals of higher generation dendrimers appear at higher field, and the protons in the interior of the molecule are thought to feel the shielding effect of the $\pi$ electrons in other aromatic rings. As the signals in P1 appear downfield from those in DenG1-OH, the protons in $\mathbf{P 1}$ are barely shielded by the $\pi$ electrons in other aromatic rings, which exist in the surroundings. Therefore, almost all the dendritic units in $\mathbf{P 1}$ are thought to be near chain ends, and the hyperbranched polymer shown in Figure 1 is proposed as that with such a structure, of which the DB is about $50 \%$.

The present $\mathrm{DB}$ value (0.52) was higher than those of the hyperbranched polymers prepared by self-condensation of $\mathrm{AB}_{2}$ monomers, which had one aromatic fluoride and two hydroxyl groups, in the presence of potassium carbonate. The DB values

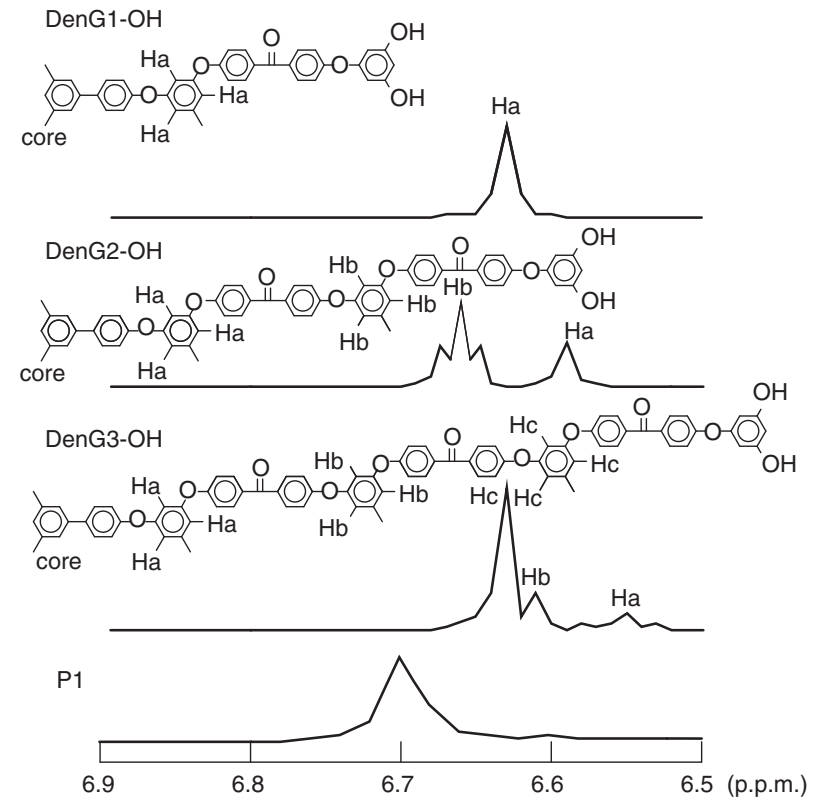

Figure 5 Comparison of ${ }^{1} \mathrm{H}-\mathrm{NMR}$ spectra for dendritic units in the hyperbranched polymer P1 with those for DenG1-0H, DenG2-OH and DenG3-OH.

were 0.15 and 0.17 in the preparation of the hyperbranched poly(ether ketone $)^{9}$ from 3,5-dihydroxy-4'-fluorobenzophenone and hyperbranched poly(ether sulfone $)^{41}$ from 4 -(3,5-dihydroxyphenoxy)$4^{\prime}$-fluorodiphenylsulfone), respectively. In the preparation of hyperbranched poly(ether sulfone), 4-fluorophenylsulfonyl groups reacted with potassium phenolates in situ. The formation of linear units by the reaction with the monophenolates was suggested to be advantageous due to low solubility of diphenolates, which formed dendritic units. In the present preparation of P1, 4-fluorbenzoyl groups reacted with potassium phenolates in situ, and reactivity of 4-fluorbenzoyl groups was lower than 4-fluorophenylsulfonyl groups due to weak electron-withdrawing of the carbonyl groups. The 4-fluorbenzoyl groups did not react with monophenolate completely in the reaction condition $\left(160^{\circ} \mathrm{C}\right)$, and the rest of them were thought to be able to react with the phenolate derived from the hydroxyl group in the linear units. Consequently, the DB value of P1 was thought to be higher than that of poly(ether sulfone) prepared in the presence of potassium carbonate. In the preparation of the hyperbranched poly(ether ketone $)^{9}$ from 3,5-dihydroxy-4'-fluorobenzophenone, the polymerization was performed at higher temperature $\left(200{ }^{\circ} \mathrm{C}\right)$, and the 4-fluorobenzoyl groups were thought to react with the monophenolate almost completely. The hyperbranched polymer with low DB value was generated as a result. The reactivity of aromatic fluorides might affect $\mathrm{DB}$ values.

\section{Properties of hyperbranched polymers}

Hyperbranched polymers resemble dendrimers in many physical properties, such as high solubility, low solution viscosity and absence of entanglement. ${ }^{40}$ The reduced viscosity of the hyperbranched polymer P1 was compared with that of the corresponding dendrimer Den G3-OH (Figure 6). Though neither viscosity was dependent on the concentration, the viscosity of $\mathbf{P 1}$ was 0.15 , and higher than that (0.10) (Morikawa et al. ${ }^{38}$ ) of DenG3-OH. The Gel permeation chromatography chromatogram shows that the size of P1 in tetrahydrofuran is smaller than that of DenG3-OH (Figure 2). The viscosity of $\mathbf{P 1}$ was higher in spite of its smaller size. The higher 


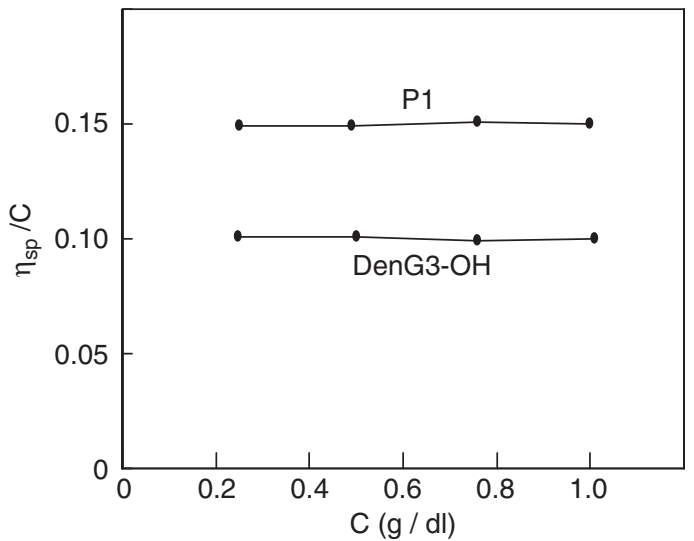

Figure 6 Reduced viscosities of the hyperbranched polymer P1 and DenG3-OH.

viscosity of P1 suggested a higher degree of interaction with the solvents, and the molecular structure in the solution was thought to be affected by the viscosities.

The thermal behavior of $\mathbf{P 1}$ was evaluated by differential scanning calorimetry, and P1 showed a glass transition $(\mathrm{Tg})$ at $190{ }^{\circ} \mathrm{C}$ (Figure 9). The $\mathrm{Tg}$ value was higher than that of DenG3-OH $\left(140{ }^{\circ} \mathrm{C}\right.$ ) (Morikawa et $\left.a l^{38}\right)$, and suggested a higher degree of interaction among molecules. As Tg vales was greatly dependent on the molecular structure, density functional theory (DFT) calculations were carried out as implemented in the Gaussian09W package of quantum chemical programs. The optimized structure of the hyperbranched polymer, which was proposed on the basis of ${ }^{1} \mathrm{H}$ NMR chemical shifts of the dendritic unit, was obtained by the RHF/ 6-31G method in the gas phase (Figure 7). Long side-chains exist in the molecule, and the possibility of entanglement among the molecules was suggested. The comparison between hyperbranched polymers and the corresponding dendrimers can be also performed in polyesters from 3,5-dihydroxybenzoic acid, poly(ether ketone)s from 3,5-bis(4-fluorophenyl)phenol and polyamides from 3,5-diaminobenzoic acid. The $\mathrm{Tg}$ value of hyperbranched polyester ${ }^{1}$ was $197^{\circ} \mathrm{C}$, and almost the same as that $\left(201^{\circ} \mathrm{C}\right)$ of the corresponding dendrimer ${ }^{42}$ possessing 48 hydroxyl groups. The $\mathrm{Tg}$ value of hyperbranched poly(ether ketone $)^{8}$ was $144^{\circ} \mathrm{C}$, and higher than that $\left(123^{\circ} \mathrm{C}\right)$ of the corresponding dendron ${ }^{43}$ possessing 16 phenoxy groups. The $\mathrm{Tg}$ value of hyperbranched polyamide ${ }^{7}$ was $305^{\circ} \mathrm{C}$, and higher than that $\left(275^{\circ} \mathrm{C}\right)$ of the corresponding dendron ${ }^{7,44}$ possessing 32 benzamide groups. Most of the hyperbranched polymers had higher Tg values than the corresponding dendrimers or dendrons, and the difference in $\mathrm{Tg}$ value between the present $\mathbf{P 1}$ and DenG3-OH was the largest. $4,4^{\prime}$-benzophenone units may contribute to the formation of the long side chains.

The solubility of P1 was compared with that of DenG3-OH (Table 1). P1 was insoluble in non-polar solvents, such as chloroform and toluene, and soluble in amide solvents, pyridine and tetrahydrofuran, and showed similar solubility as DenG3-OH. However, DenG3-OH was soluble in methanol and aqueous $\mathrm{NaOH}$ solution at room temperature, whereas $\mathbf{P 1}$ was insoluble in methanol and soluble in aqueous $\mathrm{NaOH}$ solution upon heating.

\section{Chemical modification of hyperbranched polymer}

Hyperbranched polymers based on $\mathrm{AB}_{\mathrm{n}}$ monomers are characterized by a large number of chain end groups, and the chain end groups have an important role in determining the final properties of the

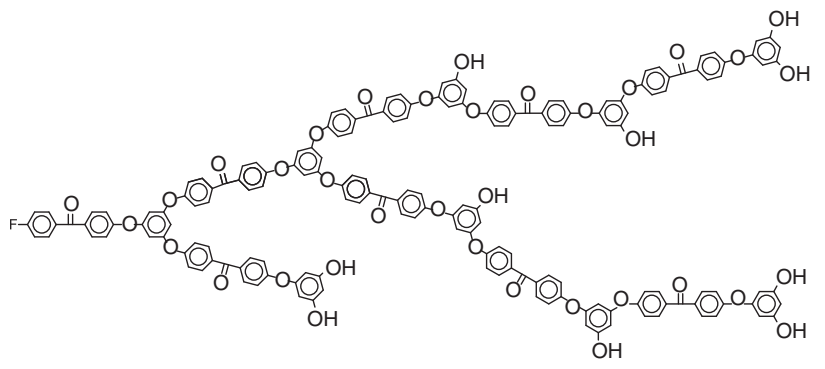

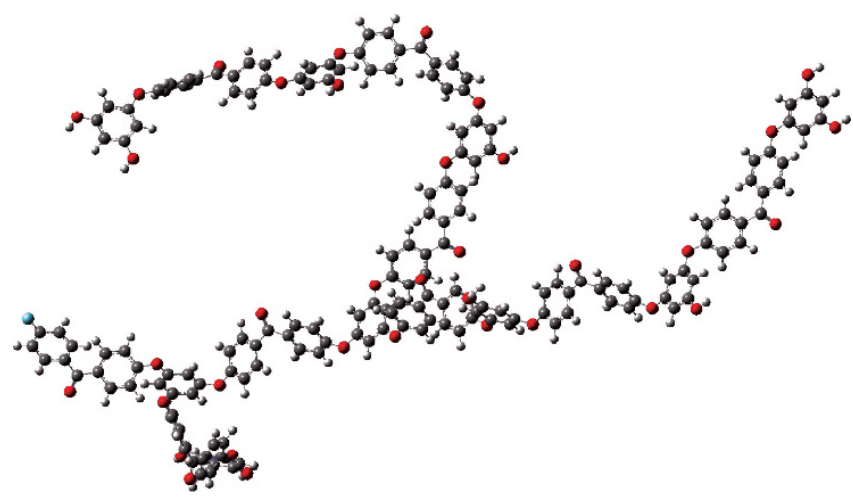

Figure 7 Optimized structure of the hyperbranched polymer.

Table 1 Solubility of hyperbranched polymers P1, P2, P3 and P4 and dendrimer DenG3-OH

\begin{tabular}{|c|c|c|c|c|c|c|c|c|}
\hline & $N M P$ & $D M A C$ & $\mathrm{CHCl}_{3}$ & pyrideine & THF & toluene & $\mathrm{CH}_{3} \mathrm{OH}$ & $\begin{array}{c}\mathrm{NaOH} \\
\text { aquation }\end{array}$ \\
\hline P1 & ++ & ++ & -- & ++ & ++ & -- & -- & + \\
\hline $\begin{array}{l}\text { DenG3- } \\
\mathrm{OH}\end{array}$ & ++ & ++ & -- & ++ & ++ & -- & ++ & ++ \\
\hline P2 & ++ & ++ & ++ & ++ & ++ & ++ & -- & -- \\
\hline P3 & + & + & ++ & ++ & ++ & ++ & -- & -- \\
\hline P4 & ++ & ++ & ++ & ++ & ++ & ++ & -- & -- \\
\hline
\end{tabular}

Abbreviations: DMAc, $\mathrm{N}, \mathrm{N}$-dimethylacetamide; NMP, $\mathrm{N}$-methyl-2-pyrrolidinone; THF, tetrahydrofuran.

Solubility: ++ , soluble at room temperature; + , soluble on heating, -- , insoluble.

polymers. As shown in Figure 8, a variety of different functional groups were introduced into P1. Hyperbranched polymers P2, P3 and P4, with methoxy groups, $n$-hexyloxy groups and benzoyloxy groups, could be prepared by the addition of methyl sulfate, 1-bromohexane and benzoyl chloride, respectively, to the reaction mixture at the end of the polymerization of $1 .{ }^{1} \mathrm{H}-\mathrm{NMR}$ analysis confirmed that the hydroxyl groups were quantitatively converted.

Properties of hyperbranched polymers are affected by the functionality of the terminal groups. The $\mathrm{Tg}$ values determined by differential scanning calorimetry of these hyperbranched polymers were dependent on the chain ends, and decreased as chain end polarity became lower. The Tg of P1, which had hydroxyl groups, was $190^{\circ} \mathrm{C}$, whereas the $T$ g values of $\mathbf{P} 2, \mathbf{P} 3$ and $\mathbf{P 4}$, which had less polar terminal groups such as methoxy groups, $n$-hexyloxy groups and benzoyloxy groups, were 160,100 and $165^{\circ} \mathrm{C}$, respectively (Figure 9). The $\mathrm{Tg}$ value of $\mathbf{P} 2$, as well as P1, was higher than that $\left(101^{\circ} \mathrm{C}\right)^{38}$ of the corresponding dendrimer DenG3-OMe. 


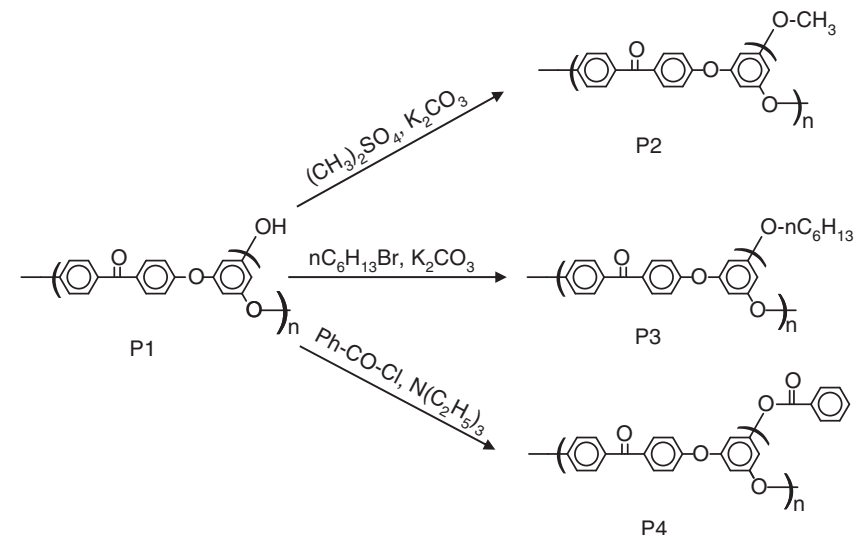

Figure 8 Chemical modification of hyperbranched polymer.

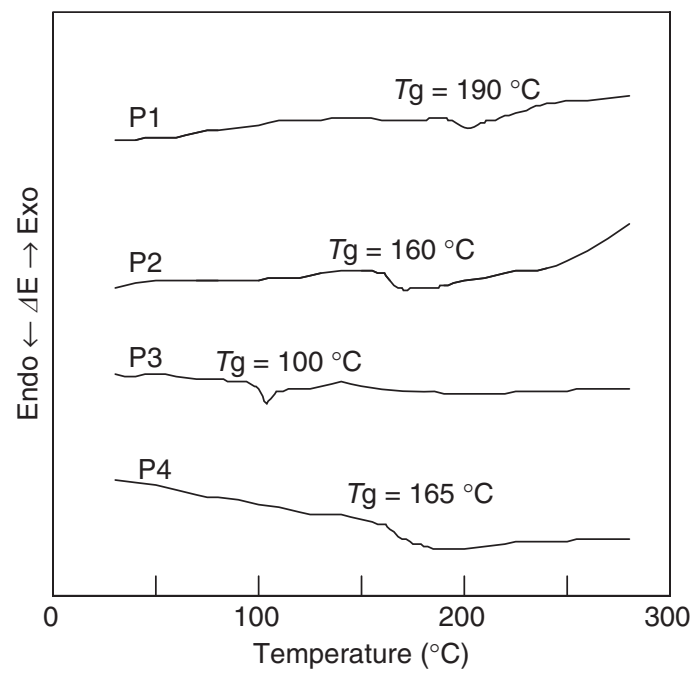

Figure 9 Differential scanning calorimetry curves of hyperbranched polymer $\mathrm{P} 1, \mathrm{P} 2, \mathrm{P} 3$ and P4.

The chain end groups had influence on the solubility of the hyperbranched polymers (Table 1). P1 was insoluble in non-polar solvents such as chloroform and toluene, whereas $\mathbf{P} 2, \mathbf{P} 3$ and $\mathbf{P} 4$ were soluble. P2 and P4, as well as P1, were soluble in polar solvents, NMP and DMAc, whereas P3 was soluble in NMP and DMAc upon heating above $100{ }^{\circ} \mathrm{C}$, and precipitated upon cooling.

\section{Thermal stabilities of hyperbranched polymers}

The thermal stabilities of $\mathbf{P} \mathbf{1}$ and $\mathbf{P} \mathbf{2}$ were compared with the corresponding dendrimers, DenG3-OH and DenG3-OMe by TG, respectively (Figure 10). P1 initiated to lost weight at $315^{\circ} \mathrm{C}$, and completed thermal decomposition at $578^{\circ} \mathrm{C}$. P2 initiated to lost weight at $355^{\circ} \mathrm{C}$, and completed thermal decomposition at $628^{\circ} \mathrm{C}$. Though the hyperbranched polymer $\mathbf{P} 1$ and $\mathbf{P 2}$ initiated thermal decomposition at lower temperature than the corresponding dendrimers, the thermal decomposition proceeded more slowly.

\section{CONCLUSION}

Hyperbranched poly(ether ether ketone)s with hydroxyl terminal groups were prepared by a one-step synthesis of an $\mathrm{AB}_{2}$-type monomer 3,5-dihydroxy-4'-(4-fluorobenzoyl)diphenylether through
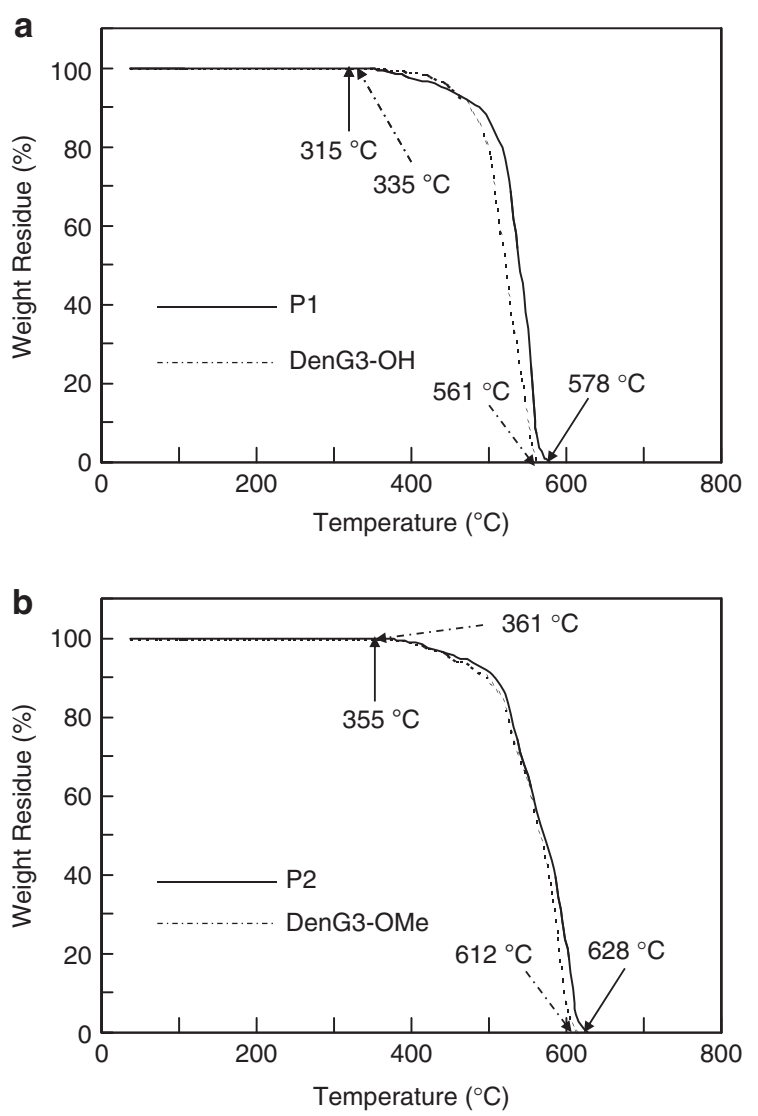

Figure 10 Comparison of TG curves between hyperbranched polymers and dendrimers. (a) P1 and DenG3-OH and (b) P2 and DenG3-OMe.

an aromatic nucleophilic substitution reaction. The degree of branching determined by ${ }^{1} \mathrm{H}-\mathrm{NMR}$ analysis was about $52 \%$. The glass transition temperatures of the hyperbranched polymers were higher than those of the dendrimers and the possibility of entanglement among the hyperbranched polymer molecules was suggested. The optimized structure of the hyperbranched polymers, which was proposed on the basis of the ${ }^{1} \mathrm{H}-\mathrm{NMR}$ chemical shifts of the dendritic units, supported this hypothesis. The hydroxyl groups at the chain ends were converted into a variety of functional groups. The nature of the chain end was shown to affect the glass transition temperatures and solubilities of the hyperbranched polymers.

1 Hawker, C. J., Lee, R. \& Frechet, J. M. J. One-pot synthesis of hyperbranched polyester J. Am. Chem. Soc. 113, 4583-4588 (1991).

2 Turner, S. R., Viot, B. I. \& Mourey, T. H. All-aromatic hyperbranched polyesters with phenol and acetate and groups: Synthesis and characterization. Macromolecules 26, 4617-4623 (1993).

3 Malmstrom, E., Johansson, M. \& Hult, A. Hyperbranched aliphatic polyester. Macromolecules 28, 1698-1703 (1995).

4 Ishida, Y., Jikei, M. \& Kakimoto, M. Synthesis of hyperbranced aromatic polyester by carbon monoxide insertion reaction using palladium catalyst. Poly. Adv. Technol 11, 684-704 (2000).

5 Yang, G., Jikei, M. \& Kakimoto, M. Successful terminal self-condensation of AB2 monomer to form hyperbranched aromatic polyamide. Macromolecules 31 5964-5966 (1998).

6 Yang, G., Jikei, M. \& Kakimoto, M. Synthesis and properties of hyperbranched aromatic polyamide. Macromolecules 32, 2215-2220 (1999).

7 Ishida, Y., Sun, A. C. F., Jikei, M. \& Kakimoto, M. Synthesis of hyperbranced aromatic polamides starting from dendrons as ABx monomers: effect of monomer multiplicity on the degree of branching. Macromolecules 33, 2832-2838 (2000). 
8 Miller, T. M., Neenan, T. X., Kwock., E. W. \& Stein, S. M. Dendritic analogs of engineering plastics: A general one-step synthesis of dendritic polyaryl ethers. J. Am. Chem. Soc. 115, 356-357 (1993).

9 Hawker, C. J. \& Chu, F. Hyperbranched poly(ether ketones): manipulation of structure and physical properties. Macromolecules 29, 4370-4380 (1996).

10 Morikawa, A. Preparation and properties of hyperbranched poly(ether ketones) with a various number of phenylene units. Macromolecules 31, 5999-6009 (1998).

11 Shu, C. F. \& Leu, C. M. Hyperbranched poly(ether ketone) with carboxylic acid terminal groups: synthesis, characterization, and derivation. Macromolecules 32, 100-105 (1999).

12 Kim, Y. H. \& Webster, O. W. Hyperbranched polyphenylenes. Macromolecules 25, 5561-5572 (1992).

13 Spindler, R. \& Frechet, J. M. J. Synthesis and characterization of hyperbranched polyurethanes from blocked isocyanate monomers by step-growth polymerization. Macromolecules 26, 4809-4813 (1993).

14 Yamanaka, K., Jikei, M. \& Kakimoto, M. Preparation and properties of hyperbranched aromatic polyimides via polyamic acid methyl ester precursor. Macromolecules 33, 6937-6944 (2000)

15 Yamanaka, K., Jikei, M. \& Kakimoto, M. Synthesis of hyperbranched aromatic polyimides via polyamic acid methyl ester precursor. Macromolecules 33, 1111-1114 (2000)

16 Yamanaka, K., Jikei, M. \& Kakimoto, M. Preparation of hyperbranched aromatic polyimides without linear units by end capping reaction. Macromolecules 34, 3910-3915 (2001).

17 Bolton, D. H. \& Wooley, K. L. Synthesis and characterization of hyperbranched polycarbonates. Macromolecules 30, 1890-1896 (1997).

18 Kim, K., Jikei, M. \& Kakimoti, M. Preparation and properties of novel hyperbranched poly(dimethylsiloxane). Polym. J. 34, 275-279 (2002).

$19 \mathrm{Kim}$, K., Jikei, M. \& Kakimoti, M. Synthesis and properties of amphiphilic hyperbranched poly(dimethylsiloxane) possessing hydrophilic and terminal group. Polym. J. 34, 755-760 (2002).

20 Hong, C., Jikei, M. \& Kakimoto, M. Synthesis of characterization of hyperbranched polybenzoxazoles. J. Photopolym. Sci. Technol. 15, 219-222 (2002).

21 Hong, C. S., Jikei, M., Kikuch, R. \& Kakimoto, M. Chemically amphified photosensitive polybenzoxazoles based on tert-butoxycarbonyl protevted hyperbranched poly (o-hydroxyamide)s. Macromolecules 36, 3174-3179 (2003).

22 Jikei, M., Mori, R., Kawauchi, S. \& Kakimoto, M. Synthesis and properties of hyperbranched poly(triphenylamine)s prepared by palladium catalyzed $\mathrm{C}-\mathrm{N}$ coupling reaction. Polym. J. 34, 550-557 (2002)

23 Takeuchi, M., Jikei, M. \& Kakimoto, M. Preparation of hyperbranched aromatic poly(ether sulfone)s possessing sulfonic acid terminal groups for polymer electrolyte. Chem. Lett. 32, 242-243 (2003).

24 Jikei, M., Chon, S.-H., Kakimoto, M., Kawauchi, S., Imase, T. \& Watanabe, J. Synthesis of hyperbranched aromatic polyamides from aromatic diamines and trimesic acid. Macromoleules 32, 2061-2064 (1999).

25 Hao, J., Jikei, M. \& Kakimoto, M. Synthesis and comparison of hyperbranched aromatic polyimides having the same repeating unit by $\mathrm{AB}_{2}$ self-polycondensation and $\mathrm{A}_{2}+\mathrm{B}_{3}$ polycondensation. Macromoleules 36, 3519-3528 (2003).

26 Sinananwanich, W., Higashihara, T. \& Ueda, M. Synthesis of a hyperbranched polymer with perfect branching based on piperidine-4-one. Macromolecules 42, 994-1001 (2009).
27 Sagawa, Y., Higashihara, T. \& Ueda, M. Hyperbranched polymers with controlled degree of branching 0 to $100 \%$. J. Am. Chem. Soc. 132, 11000-11001 (2010).

28 Tian, W., Fan, X., Kong, J., Liu, $Y$ \& Hung, $Y$ Novel supramolecular system of amphiphilic hyperbranched polymer with $\beta$-cyclodextrine and hyperbranched topography cavites: Synthesis and selective encapsulation. Polymer (Guildf) 51, 2556-2564 (2010).

29 Kaneko, R., Jikei, M. \& Kakimoto, M. Preparation and properties of composite materials composed aromatic polyamides and vinyl polymers. High Perform. Polym. 14, 41-51 (2002).

30 Kaneko, R., Suzuki, E., Jikei, M. \& Kakimoto, M. Preparation and properties of hyperbranched aromatic polyamide-silica composites by sol-gel method. High Perform. Polym. 14, 105-114 (2002).

31 Gao, H., Yorifuji, D., Wakita, J., Jiang, Z. H. \& Ando, S. In situ preparation of nano $\mathrm{ZnO}$ /hyperbranched polyimide hybrid film and their optical properties. Polymer (Guildf) 51, 3173-3180 (2010).

32 Kakimoto, M., Grunzinger, S. J. \& Hayakawa, T. Hyperbranched poly(ether sulfone)s: preparation and application to ion-exchange membranes. Polym. J. 42, 697-705 (2010).

33 Kaneko, R., Jikei, M. \& Kakimoto, M. Preparation and properties of photosensitive polymers based on hyperbranched aromatic polyamides. High Perform. Polym. 14, 53-62 (2002)

34 Xie, J., Deng, X., Cao, Z., Shen, Q., Zhang, W. \& Shi, W. Synthesis and second-order nonlinear optical properties of hyperbranched polymers containing pendant azobenzene chromophores. Polymer (Guildf) 48, 5988-5993 (2007).

35 Wen, G. A. Xin, Y. Zhu, X. R., Zeng W. J., Zhu, R., Feng J. C. Cao, Y, Zhao, L., Wang, L. H., Wei, W., Peng, B. \& Hung, W. Hyperbranched triazine-containing polyfluorene: Efficient blue emitters for polymer light-emitting diodes (PLEDs). Polymer (Guildf) 48, 1824-1829 (2007)

36 Taniguchi, Y., Shirai, K., Saitoh, H., Yamaguchi, T. \& Tubokawa, N. Postgrafting of vinyl polymers onto hyperbranched poly(amino-amido)-grafted nano-sized silica surface. Polymer (Guildf) 46, 2541-2547 (2005).

$37 \mathrm{Oh}$, J. H., Jang, J. \& Lee, S. H. Curing behavior of tetrafunctional epoxy resin/hyperbranched polymer system. Polymer (Guildf) 42, 8339-8347 (2001).

38 Morikawa, A. \& Ono, K. Preparation of poly(ether ether ketone) dendrimers by the divergent Method. Polym. J. 32, 234-242 (2000).

39 Morikawa, A. \& Ono, K. Preparation of poly[(ether)-(ether ether ketone)]dendrimers by the convergent method. Polym. J. 32, 255-262 (2000).

40 Ishizu, K., Shibuya, T. \& Mori, A. Synthesis and characterization of hyperbranched poly(ethyl methacrylate) by quasi-living radical polymerization of photofunctional inimer. Polym. Int. 51, 424-428 (2002).

41 Jikei, M., Uchida, D., Haruta, Y., Takahashi, Y. \& Matsumoto, K. Synthesis and properties of hyperbranched poly(ether sulfone)s prepared by self-polycondensation of novel AB2 monomer. J. Polym. Sci. Part A, Polym. Chem. 50, 3830-3839 (2012).

42 Hawker, C. J. \& Frechet, J. M. Monodispersed dendritic polyesters with removable chain ends; a versatile approach to globular macromolecules with chemically reversible polarities. J. Chem. Soc. Perkin. Trans. 1, 2459-2469 (1992).

43 Morikawa, A., Kakimoto, M. \& Imai, Y. Convergent synthesis of starburst poly(ether ketone) dendrons. Macromolecules 26, 6324-6329 (1993).

44 Ishida, Y., Jikei, M. \& Kakimoto, M. Rapid synthesis of aromatic polyamide dendrimers by orthogonal and a double-stage convergent approach. Macromolecules 33, 3202-3211 (2000). 